\title{
Correction to: Crystallization Kinetics and Mechanical Properties of Nougat Creme Model Fats
}

\section{Stephen-Sven Hubbes ${ }^{1} \cdot$ André Braun $^{2} \cdot$ Petra Foerst $^{3}$}

Published online: 7 August 2019

(C) Springer Science+Business Media, LLC, part of Springer Nature 2019

\section{Correction to: Food Biophysics} https://doi.org/10.1007/s11483-019-09596-w

The original version of this article unfortunately contained errors. During final layout the format of Table 1 was displaced and an odd symbol was inserted in Eq. 2. The correct versions are given below.

$G^{\prime} \sim \Phi^{1 /(d-D)} \sim \tau_{0}$

Publisher's Note Springer Nature remains neutral with regard to jurisdictional claims in published maps and institutional affiliations.

The online version of the original article can be found at https://oi.org/ 10.1007/s11483-019-09596-w

\section{Petra Foerst}

petra.foerst@tum.de

1 Rapunzel Naturkost GmbH, Rapunzelstr. 1, 87764 Legau, Germany

2 Anton Paar Germany GmbH, Hellmuth-Hirth-Str. 6, 73760 Ostfildern-Scharnhausen, Germany

3 Lehrstuhl für Systemverfahrenstechnik, Department of Food and Life Sciences, Technical University of Munich (TUM),

85354 Freising, Germany 
Table 1 The experimental setup and the differant fat samples (with their respective Tripalmitin content) used for oscillation rheology and the isothermal DSC studies for the investigation of structural properties and crystallization kinetics

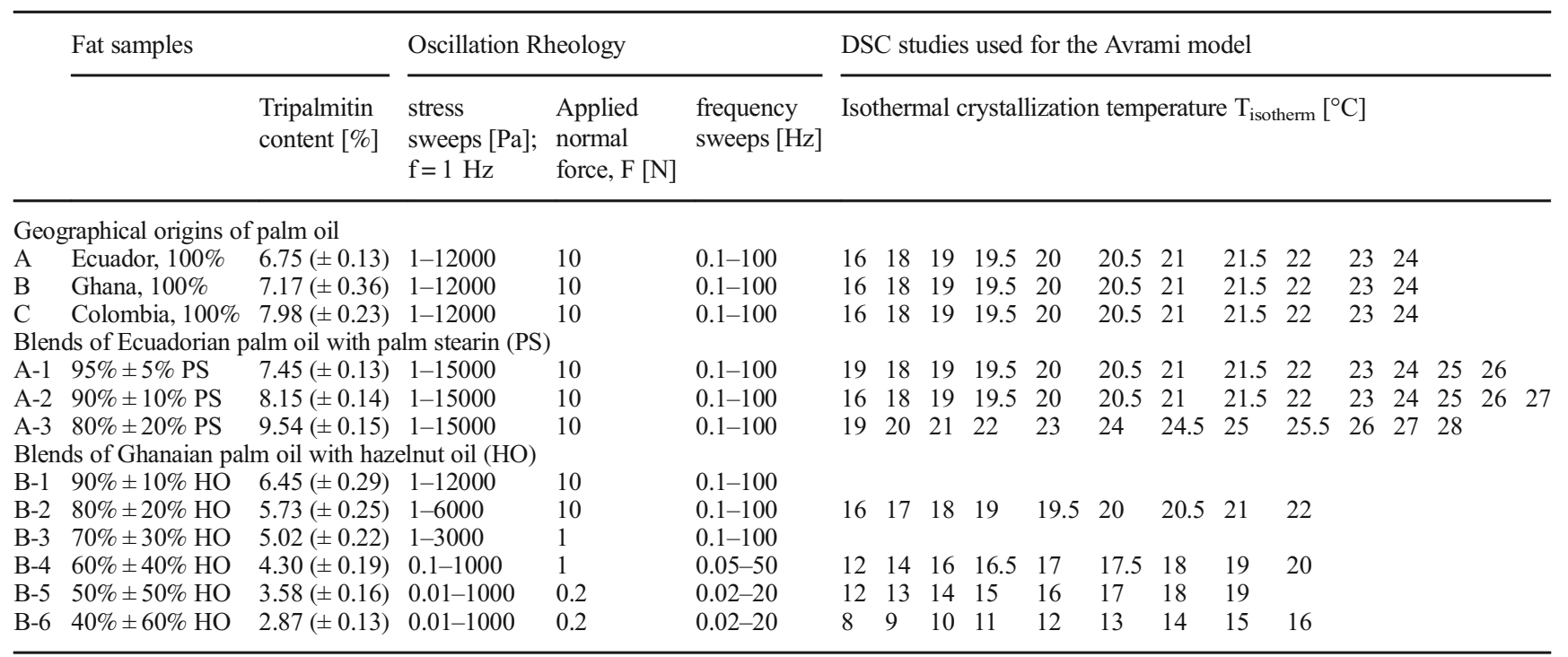

All the origins of palm oil and all the blends have been studied with triplicate measures for the DSC studies and quintuplicate measures for the rheological studies. Values in parenthesis represent confidence intervals $(\alpha=0.05)$ for the different origins of palm oil and calculated measurement failure for the blends 